\title{
Experimental Behavior of FRP Confined Concrete Cylinder Wrapped by Two Different FRPs
}

\author{
Ataur Rahman ${ }^{1}$, Madhobi Mallick ${ }^{2} \&$ Shantanu Ghosh $^{2}$ \\ ${ }^{1}$ Associate Professor, Department of Civil Engineering, KUET, Khulna, Bangladesh \\ ${ }^{2}$ Undergrad students, Department of Civil Engineering, KUET, Khulna, Bangladesh \\ Correspondance: Room No. 210, Department of Civil Engineering, Khulna University of Eng. \& Tech. (KUET), \\ Khulna 9203, Bangladesh. Tel: 88-017-1408-7309. E-mail: ataur107@yahoo.com
}

\author{
Received: January 4, 2018 \\ Accepted: January 22, 2018 \\ Online Published: February 27, 2018 \\ doi:10.5539/jmsr.v7n2p18 \\ URL: https://doi.org/10.5539/jmsr.v7n2p18
}

\begin{abstract}
This paper presents the results of experimental investigation on concrete cylinders confined with two different types of fiber reinforced polymer (FRP) sheets, they are: synthetic high strength CFRP composites and composites using natural fiber like Jute. These two FRPs are very much distinct with respect to their strength and recycle properties. Conventional FRPs like CFRP possess superior mechanical strength than natural FRPs, but have got some serious drawbacks such as high density, high cost and poor recycling and non-biodegradable properties. On the other hand, the durability of the natural fibers can be enhanced by mummification of the fibers within the epoxy resin. An experimental study was conducted, where twenty six small scale cylindrical concrete specimens $(100 \times 200 \mathrm{~mm})$ were subjected to uniaxial compression up o failure and the corresponding stress-strain behaviors were observed. The ultimate failure load and the deformation at peak load were the two important observations. The results demonstrate that a significant increase in the compressive strength can be achieved by confining the concrete with CFRP but both strength and ductility are compromised when concrete is wrapped with JUTE-FRP. However, JUTE-FRP shows reasonably good ductile behavior for the case of low strength concrete and can safely be used for brick masonry column. For low cost strengthening work, JUTE-FRP can be an alternative for low strength concrete and masonry works.
\end{abstract}

Keywords: concrete column strengthening, carbon fiber reinforced polymer (CFRP), external wrapped with Jute fiber

\section{Introduction}

In many recent earthquakes, it has been observed that buildings with relatively weak columns collapsed in a pancake fashion. This is due to the presence of soft stories and due to the presence of strong beams but comparatively weaker columns (Figure 1). In multistory reinforced concrete buildings it is desirable to form plastic hinges in beams rather than in columns to dissipate earthquake induced energy by yielding of the beams rather than the columns (Figure 2). The columns are responsible from overall strength and stability of the structure, during severe seismic zolt. Furthermore, columns are compression members and axial compression reduces the ductility of reinforced concrete columns, thus necessitating more stiff confining reinforcement. Therefore, it is preferable to control inelasticity in columns, to the extent possible, while dissipating most of the energy through yielding of the beams as a measure against total collapse of the structure (Saatcioglu, 2010). To achieve this "weak beam strong column" objective, the columns of a building can be made more stiff against deformation by wrapping them with FRPs.

Fiber reinforced polymer (FRP) is a composite material consisting of a polymer matrix imbedded with high-strength fibers, such as Glass, Aramid, Carbon, Natural fiber etc to achieve certain properties better than either of the base materials (Figure 3). The benefit of using FRPs as potential strengthening material comes from the reduction in handling costs; despite additional material costs, and they are easy to install due to light weight (Burgoyne \& Balafas, 2007).

Research on natural fiber composites has incepted long ago but has not received much attention until late in the 1980 's. There is enough potential for agro based product as an additives / reinforcement materials. Natural fibers offer many technical and ecological benefits for their use in reinforcing composites. Many types of natural fibers 
have been investigated for use in plastics including cotton, jute, kenaf, sisal, coir, etc (Malhotra, Sheikh, \& Rani, 2012). These materials are predominantly used as a replacement for conventional synthetic and petroleum based fibers. A major goal of natural fiber composites is to alleviate the use of expensive fibers which has a relatively high density and is dependent on nonrenewable sources. Therefore, natural fibers are good candidates to substitute the synthetic fibers, such as Glass and Carbon, as they have inherently lower embodied energy. In addition to that natural fibers are biodegradable or recyclable depending on the selected matrix (NGCC, 2008). Though the strength of bio-fibers is not as great as conventional fibers, the specific properties are comparable and they are compatible with conventional resins. Moreover, the durability of the natural fibers can be enhanced by mummification of the fibers within the epoxy resin.

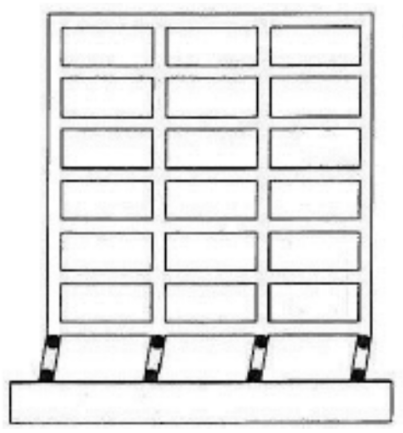

Figure 1. Mechanism of weak column strong beam in a building frame

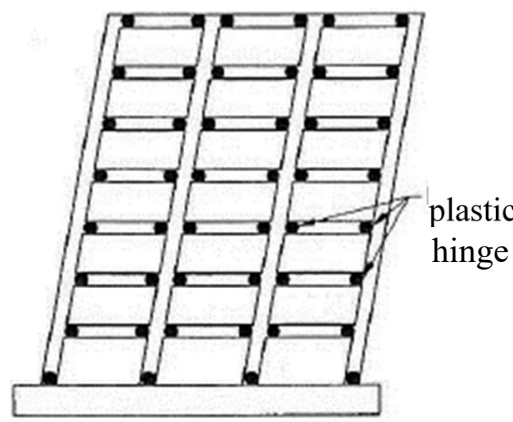

Figure 2. Mechanism of formation of plastic hinge in beams

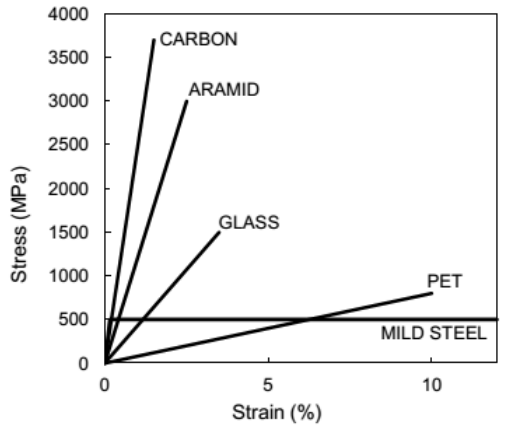

Figure 3. Tensile strength of different FRPs

The aim of seismic retrofitting is to upgrade the ultimate strength/deformation of the structure by improving the structure's ability to undergo inelastic deformation without total collapse during an earthquake. However, to date the number of primary structural applications of FRPs in construction remains relatively low and there appears to be a number of issues contributing to their slow uptake by the construction industry. Issues such as cost, absence of design codes, lack of industry standardization, poor understanding of construction issues by composites industry, Lack of designers experience with polymer composite materials are commonly claimed to place these materials at a disadvantage when considered against traditional construction materials.

Confinement has been known to add both strength and ductility in the axial direction for concrete column and this idea originally developed back in the 1920's (Richart, Brandtzaeg, \& Brown, 1928). Numerous conventional techniques e.g., ferrocement, shotcreting overlay, grout injection, external reinforcement, posttensioning, near surface retrofitting, etc. are available and getting popular for retrofitting of concrete column. In recent years, the use of fiber reinforced polymers (FRP) as an external strengthening have gained considerable popularity over conventional strengthening and repair of concrete structures. The FRP composites have been used successfully for rehabilitation and strengthening of existing reinforced concrete elements to meet the higher standard of seismic loading. One popular technique of FRP strengthening is the wrapping of reinforced concrete columns to increase their axial strength, shear strength, and seismic resistance.

In this experiment, the FRP sheets are generally wrapped around the columns with fibers oriented mainly in the circumferential (hoop) direction. The fibers confine the concrete and increase the axial strength by creating a tri-axial state of stress. The FRP wraps also increase the shear resistance of columns and prevent premature failures when columns are subjected to lateral loadings typical of those observed during earthquakes (Green, Bisby, Fam, \& Kodur, 2006). Reinforced concrete columns need to be laterally confined in order to ensure large deformation under applied loads and to provide an adequate bearing capacity. In the case of a seismic event, energy dissipation allowed by a well-confined concrete core can often save lives. On the contrary, a poorly confined concrete column behaves in a brittle manner leading to sudden and catastrophic failures (Kumutha, Vaidyanathan, \& Palanichamy, 2007) When the FRP-wrapped concrete is subjected to an axial compression loading, the concrete core expands laterally. This expansion is resisted by the FRP wrap, and therefore the concrete core is changed to a three dimensional compressive stress state. In this state, performance of the concrete core is significantly influenced by the confinement pressure (Parvin \& Jamwal, 2005).

In this study, CFRP have been used as conventional but expensive strengthening materials. On the other hand JUTE-FRP has been engaged as a low cost strengthening material. A comparison between these two FRPs in term 
compressive strength and deformation at peak load has been shown in this study. The strength of CFRP is higher than JUTE-FRP, whereas JUTE-FRP possesses natural fiber though weaker than CFRP, is quite available at low cost and has pronounced elongation at failure. The purpose of this study is to show the difference in behavior of concrete cylinder wrapped by these two distinct FRPs and the superiority of the one type of FRP over the others. Ultimate compressive load, deformation at peak load, and mode of failure, are observed in this study.

\section{Experimental Programe}

\subsection{Specimen Preparation}

A total of 26 concrete cylinders with a diameter of $100 \mathrm{~mm}$ and a height of $200 \mathrm{~mm}$ were prepared and tested under uniaxial compression loading. Four different types of mix ratio were used (Table 1). Conplast SP430A was used as water reducing admixture in due proportion. After recommended curing of 28 days, the concrete cylinders were dried for 3 days in natural air and then the externally wraps of CFRP \& JUTE-FRP were applied onto those cylinders in a single layer. Figure 4 shows the procedure of wrapping of concrete cylinder with FRP sheet. Figure 5 shows CFRP wrapping.

Table 1. Specification of mix-design for different specimen

\begin{tabular}{cccc}
\hline Specimen ID & Mix design ratio (Cement: sand: CA) & $w / c$ & 28 days strength $(\mathrm{MPa})$ \\
\hline C-13 & $1: 3.46: 3.66$ & 0.80 & 13 \\
C-18 & $1: 2.48: 2.83$ & 0.60 & 18 \\
C-25 & $1: 1.71: 2.18$ & 0.40 & 25 \\
C-35 & $1: 1.21: 1.75$ & 0.33 & 35 \\
\hline
\end{tabular}

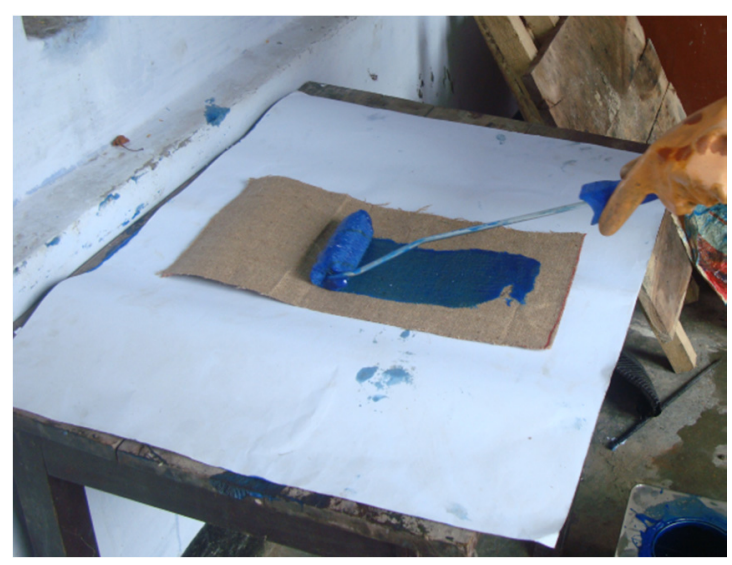

(a)

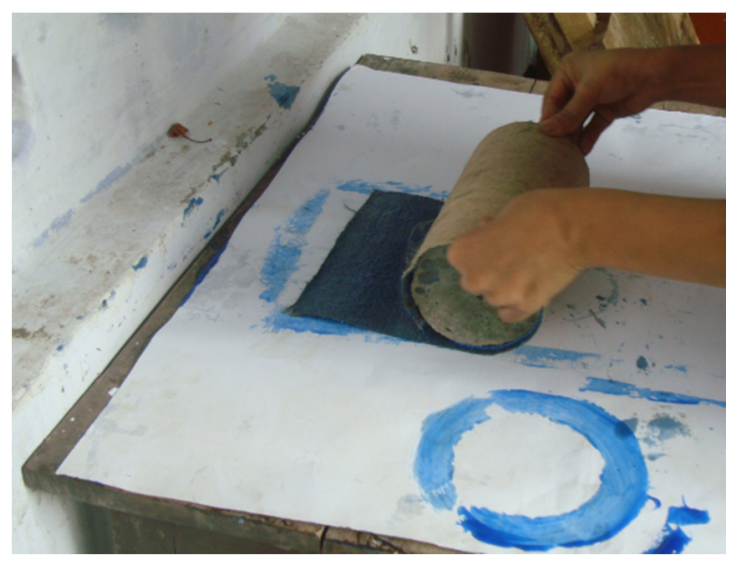

(c)

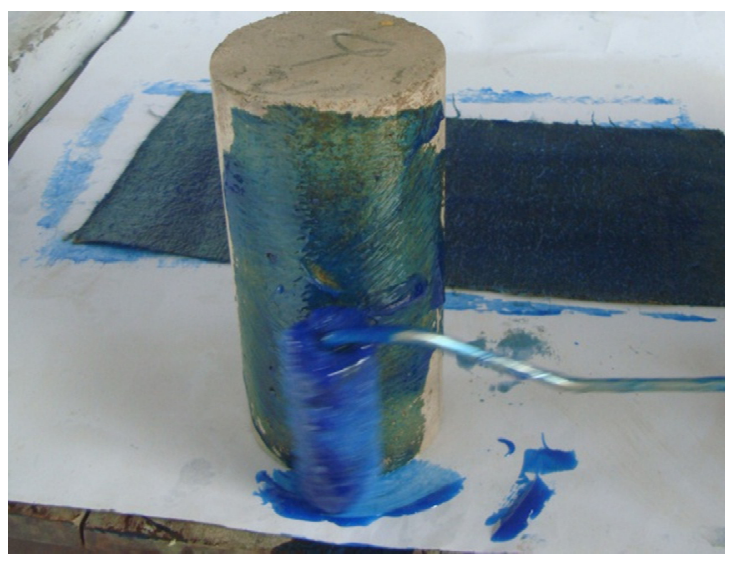

(b)

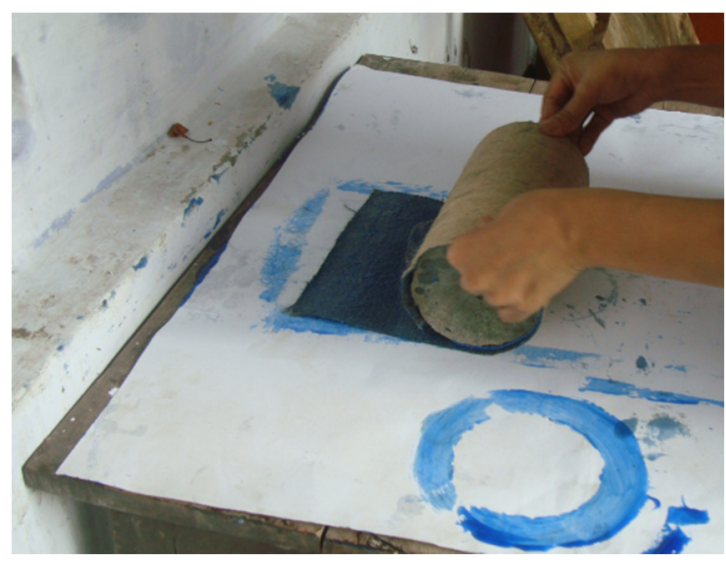

(d)

Figure 4. Application procedure of FRP on the concrete specimen, $a$ ) curing of FRP sheet with epoxy resin; $b$ ) apply resin on the surface of concrete cylinder; $c$ ) wrapping of cylinder and $d$ ) final curing with resin 


\subsection{Material Properties}

The mechanical properties of Jute, mentioned in Table 2 were evaluated following the ASTM standard testing procedures. For each case, three samples were tested and the average results of these three are posted in Table 2.

Table 2. Properties of fibers and adhesive

\begin{tabular}{llll}
\hline \multirow{2}{*}{ Properties } & FRP materials & & Adhesive \\
\cline { 2 - 4 } & CARBON $(F T S-C 1-20)$ & JUTE & RESIN $(D-90 R)$ \\
\hline Tensile strength $(\mathrm{MPa})$ & 3400 & 250 & 45 \\
\hline Elastic modulus $(\mathrm{GPa})$ & 245 & 1.6 & 1.56 \\
Elongation at fracture $(\%)$ & 1.5 & 22.7 & 28 \\
Thickness $(\mathrm{mm})$ & 0.333 & 1.304 & - \\
Width $(\mathrm{mm})$ & 250 & 500 & - \\
Stiffness $(\mathrm{kN} / \mathrm{mm})$ & 82 & 2 & - \\
\hline
\end{tabular}

\subsection{Test Setup and Loading}

An automatic hydraulic testing machine was used to perform uniaxial compression test of the cylindrical specimens, as shown in Figure 6. Load was applied at a constant rate of $5 \mathrm{kN} / \mathrm{min}$. All the necessary data were obtained through data logger as shown in Figure 7. Biaxial electrical strain gauges were used to record both the axial and lateral strains.

\section{Experimental Results and Discussion}

All of the cylindrical concrete specimens, wrapped with either CFRP or JUTE-FRP, were tested under uniaxial compression loading. The test results are given in Table 3. Confining strength in Table 3 is calculated according to the expression given in Figure 8. In this figure, $T$ is hoop tension, $\sigma_{l}$ is the lateral confining strength, $f_{f}$ tensile strength of FRP, $E_{f}$ is the modulus of FRP, $\varepsilon_{l}$ is the lateral stain, $f_{c c}$ is the confining compressive strength of FRP $t$ is the thickness of the FRP sheet and $d$ is the diameter of the cylinder.

\subsection{Behavior of Plain Specimen}

The axial stress-stain behavior of plain concrete specimens is shown in Figure 8. Concrete with higher strength shows higher stiffness. The strengths of those four types of concrete are given in Table 3. It is observed in Figure 9 that the axial strain varies between 0.175 and 0.45 percent. All of the specimens failed in crushing of aggregate.

\subsection{Behavior of FRP Wrapped Specimens}

It is quite clear from Table 3 that axial load certainly increases due to confinement of the concrete cylinder. However, the rate of increment gradually falls with the increase of unconfined concrete strength, $f_{c}$. Lower the unconfined compressive strength of concrete higher is the confining strength and for the case of low strength concrete (13 MPa) it is about $277 \%$, but for high strength concrete (35MPa), it is only $90 \%$. So it can be said that

Table 3. Test results of cylindrical specimens

\begin{tabular}{|c|c|c|c|c|c|}
\hline $\begin{array}{l}\text { Specimen } \\
\text { ID }\end{array}$ & $\begin{array}{c}\text { Compressive } \\
\text { strength } \\
(M P a)\end{array}$ & $\begin{array}{c}\text { Deformation } \\
\text { at peak load } \\
(\mathrm{mm}) \\
\end{array}$ & $\begin{array}{c}\text { Load increase } \\
(\%)\end{array}$ & Confining strength $(\mathrm{MPa})$ & Failure mode \\
\hline $\mathrm{C}-13$ & 13 & 0.20 & - & - & crushing of concrete \\
\hline CFRP-13 & 50 & 4.08 & 285 & 22.65 & crushing + rupture of FRP \\
\hline JFRP-13 & 22 & 2.70 & 69 & 6.52 & crushing + rupture of FRP \\
\hline $\mathrm{C}-18$ & 18 & 0.14 & - & - & crushing of concrete \\
\hline CFRP-18 & 54 & 6.12 & 200 & 22.65 & crushing + rupture of FRP \\
\hline JFRP-18 & 25 & 1.49 & 39 & 6.52 & crushing + rupture of FRP \\
\hline $\mathrm{C}-25$ & 25 & 0.96 & - & - & crushing of concrete \\
\hline CFRP-25 & 66 & 2.12 & 164 & 22.65 & crushing + rupture of FRP \\
\hline JFRP-25 & 32 & 0.91 & 28 & 6.52 & crushing + rupture of FRP \\
\hline $\mathrm{C}-35$ & 35 & 0.33 & - & - & crushing of concrete \\
\hline CFRP-35 & 66 & 1.65 & 89 & 22.65 & crushing + rupture of FRP \\
\hline JFRP-35 & 46 & 0.88 & 30 & 6.52 & crushing + rupture of FRP \\
\hline
\end{tabular}


CFRP confinement is more effective for low strength concrete than for the high strength concrete. One more observation can be derived from this fact that the stiffness of confining material should be higher than the concrete itself to have an effective confinement mechanism. Similar tendency can also be observed for the case of concrete cylinders confined with JUET-FRP. But in that case the rate is much lower than its counterpart CFRP The reason is quite obvious. Jute fiber is a softer material than Carbon fiber, which is why, JUTE-FRP offers less confining strength than CFRP. It is about $62 \%$ for low strength concrete and only $30 \%$ for high strength concrete. So, it can be conclude that Jute is not a good confining material as long as high strength concrete is concerned. Figure 10 depict these behaviors in a clear fashion.

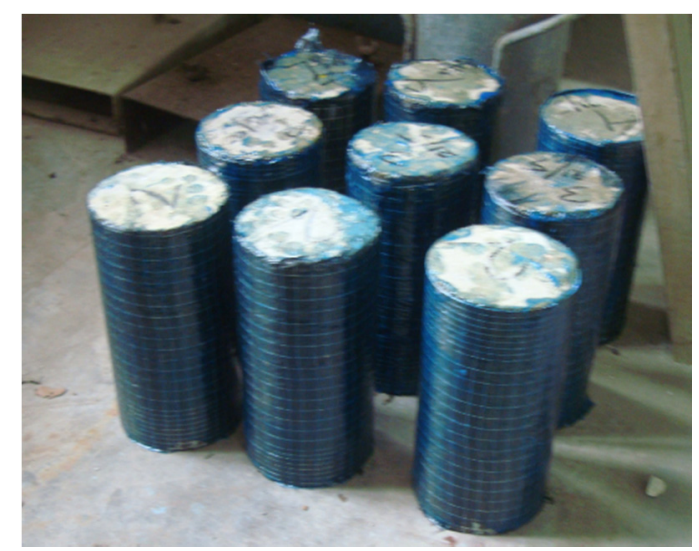

Figure 5. Concrete specimen wrapped with CFRP

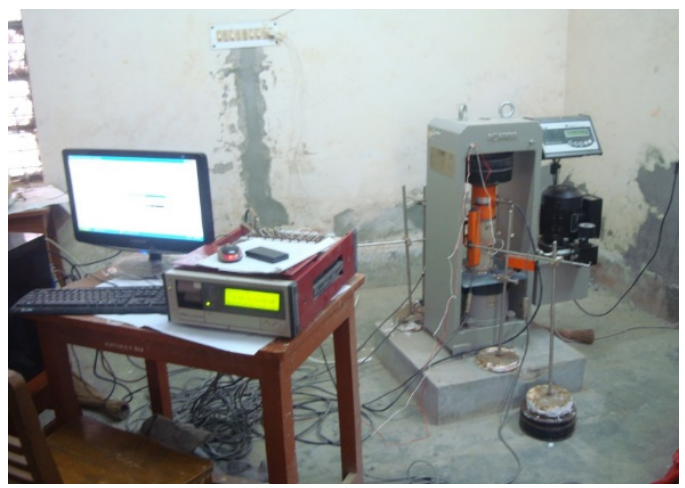

Figure 7. Data acquisition system in data logger

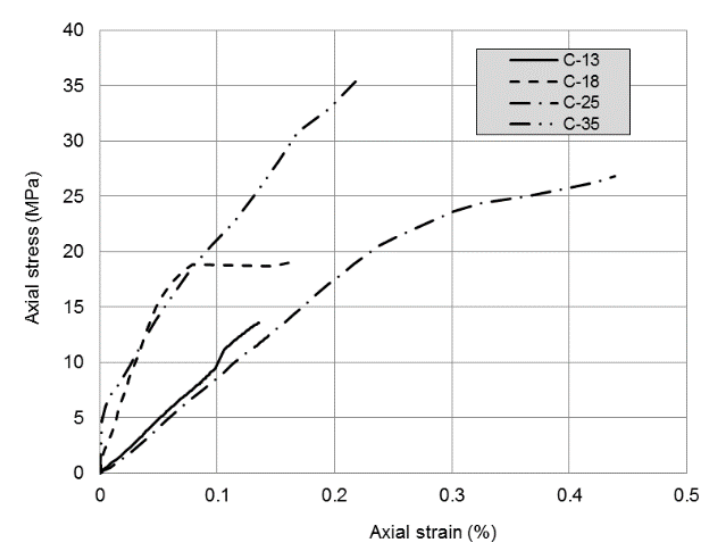

Figure 9. Stress-strain behavior of plain concrete

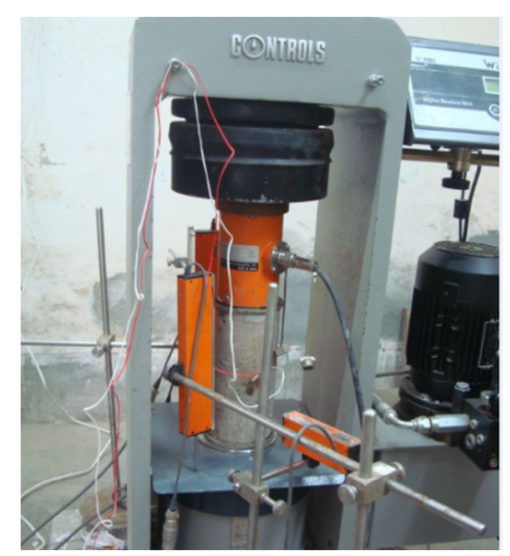

Figure 6. Compression Test of specimen

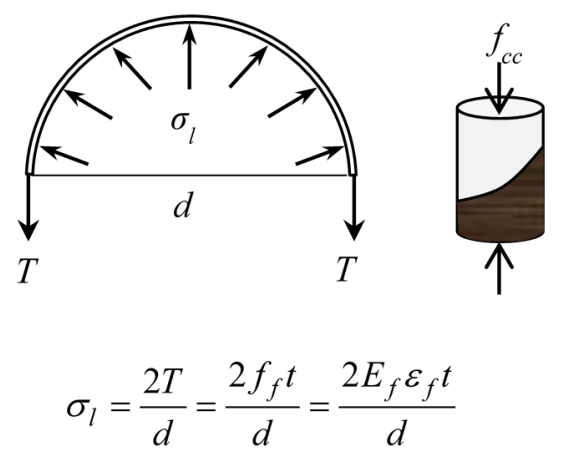

Figure 8. Confining strength in circular column

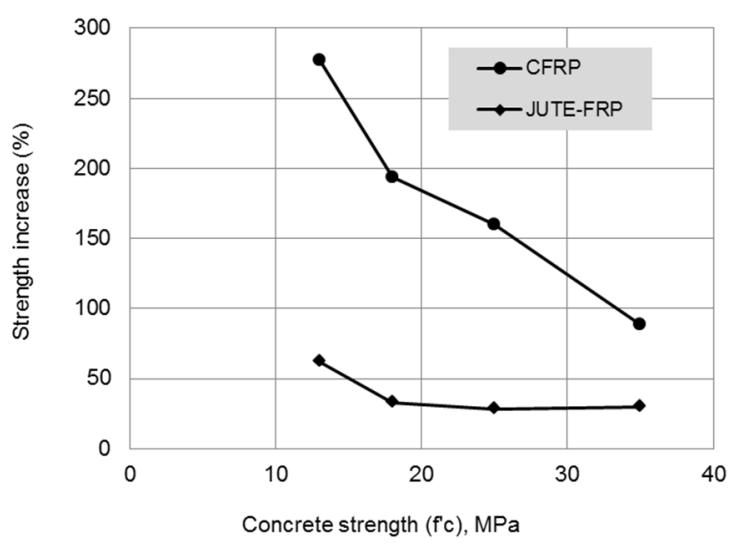

Figure 10. Confined strength vs. concrete strength 
To fully understand the behavior of CFRP wrapped confined concrete, a typical load-history diagram is shown in Figure 11. Initially the loading history traces a liner path (point $a$ ), which obviously depicts the elastic behavior of concrete. The slope of this elastic path depends on the elastic modulus and Poisson's ratio of concrete and the confining material. As the load gradually increases, the state of stress in concrete reaches to the yield surface (point $b$ ), where the plastic deformation of the concrete can be presumed. Damage in concrete in this stage can be best explained by elasto-plastic and fracture mechanism, detail of which can be found in Okamura and Maekawa (1997). After this state, a brief plastic hardening phase can be intercepted (point $c$ ) with the opening of the yield surface. When the plastic volumetric strain reaches a certain value, the hardening process comes to a cease (point $d$ ). At this stage the yield surface reaches to its most expanded shape, which is referred to as failure state. As the applied load is carried on, the softening regime is initiated, the yield surface moves parallel to the hydrostatic axis and the load-history follows a linear path (point $e$ ) as shown in Figure 11.

On the other hand, the load-history of a typical JUTE-FRP wrapped concrete specimen is shown in Figure 12, which demonstrates a different tendency than CFRP wrapped specimen. As the stiffness $\left(E_{f} t_{f}\right)$ of JUTE-FRP is quite low than its counterpart of CFRP (see Table 2), the rate of load increment goes in a steeper way while the effect of JUTE-FRP confinement on concrete is insignificant as long as the concrete behave elastically (point $a$ ). This is due to the fact that the lateral strain in concrete at any stage of stress can only produce very little axial stress in Jute fiber, as a result, generates very low confining pressure. As the confining pressure is very low, the yielding state and the subsequent plastic hardening regime (point $b$ and $c$ ) is very short lived and the concrete proceed to softening path quite early (point $e$ ). So it can be said that jute is not an effective confining material for concrete and doesn't impart any ductility to the concrete.

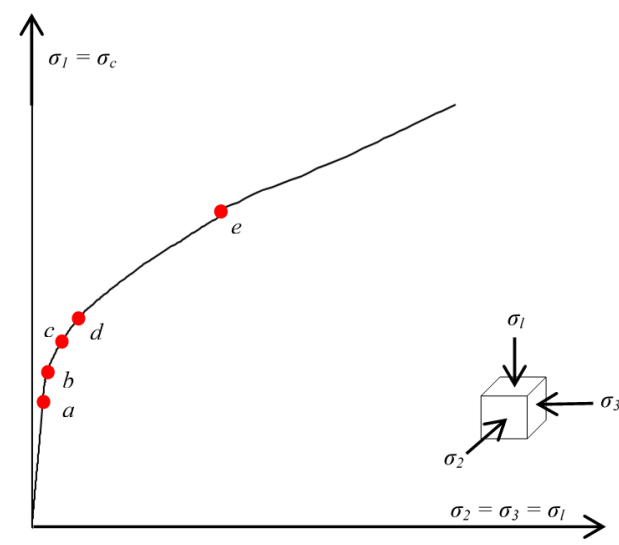

Figure 11. Typical loading path for a CFRP wrapped specimen

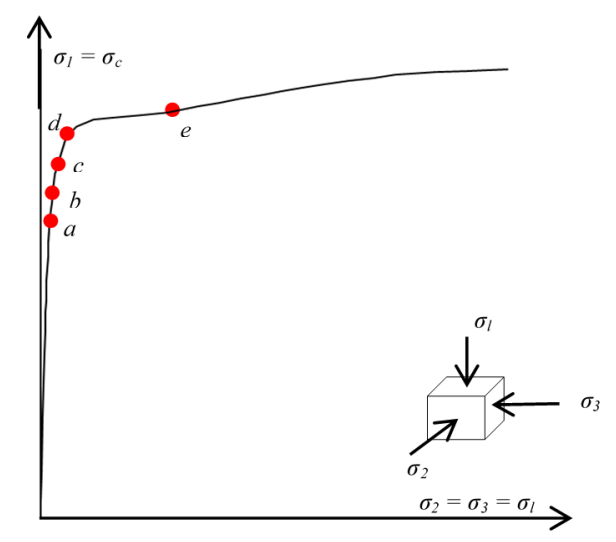

Figure 12. Typical loading path for a JUTE-FRP wrapped specimen

\subsection{Stress-strain Behavior and Failure Pattern}

The stress-strain characteristics of plain concrete as well as FRP confined concrete are shown in Figure 13. It is evident from Figure 13 that CFRP wrapping offers both strength and ductility to the concrete without compromising the essential objectives of column strengthening i.e stiffness and plasticity. One more interesting point here to note that for low strength concrete CFRP wrapped offer more ductility than for the high strength concrete. On the other hand JUTE-FRP wraps offer less strength and less ductility. For low strength concrete JUTE-FRP can shows little ductile behavior but for high strength concrete the ductility is compromised. So, it can be conclude that Jute is not an effective strengthening material for concrete column. Both the CFRP and JUTE-FRP demonstrate the similar failure pattern as shown in Figure 14 and they are the complete rupture of FRP along the length of the specimen which can be characterize as hoop tension failure. For the case of CFRP, the only difference is that, here the stress concentration took place at the top of the specimen and as a consequence the hoop stress reached to its peak which is tantamount to the tensile strength of the CFRP material. At the time of evolution of failure process, no debonding of the FRPs were noticed either of the specimens but a sudden and explosive nature of failure was observed which indicates the release of excessive amount of energy as a result of the uniform confining stress without significant debonding in the wrap. So, it can be said that CFRP wrapping is very effective for concrete column when the shape of the column is circular. Similar observation was also reported by Rahai, Sadeghian, and Ehsani (2008). 

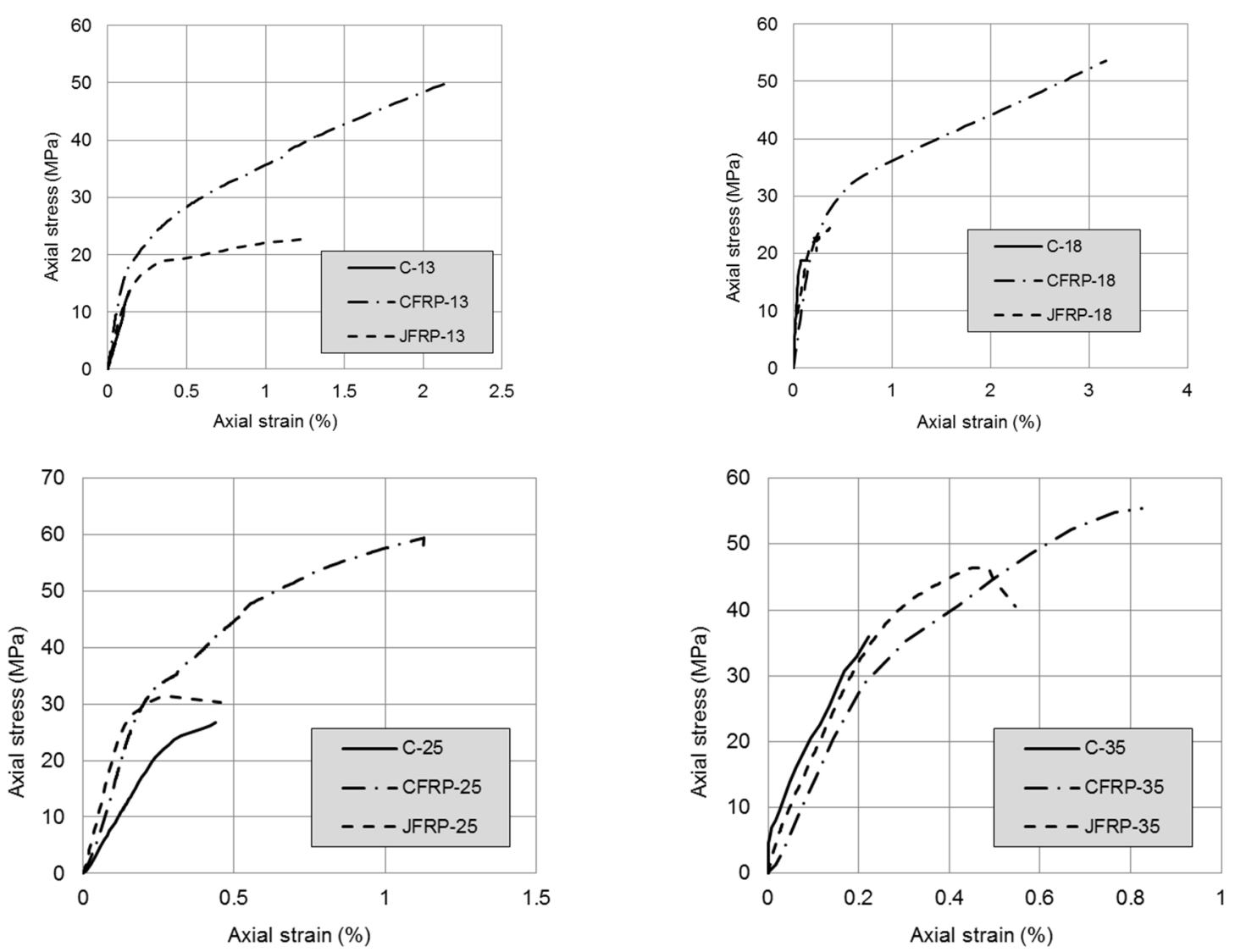

Figure 13. Stress-strain characteristics of plain concrete as well as concrete wrapped with CFRP and JUTE-FRP for different concrete strengths

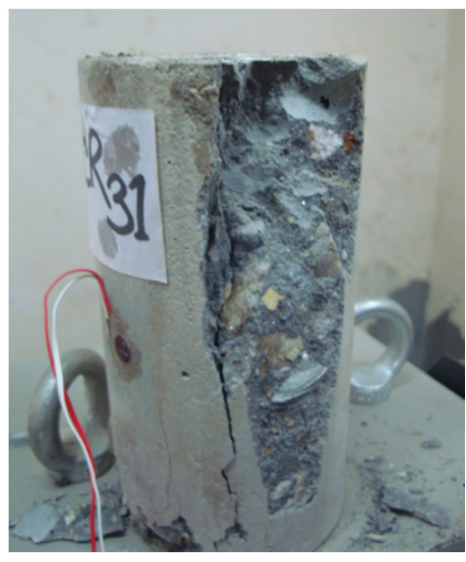

a)

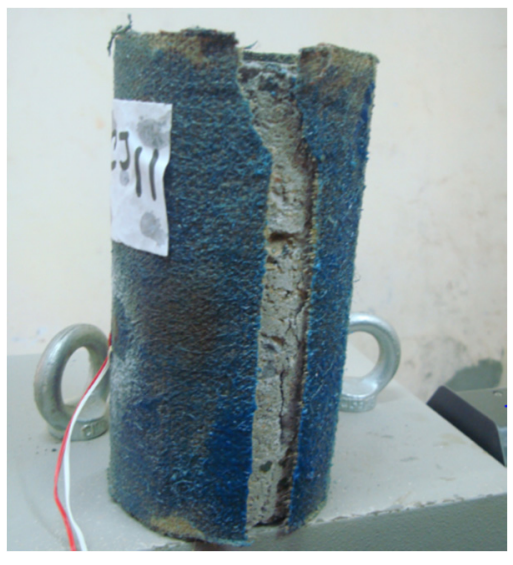

b)

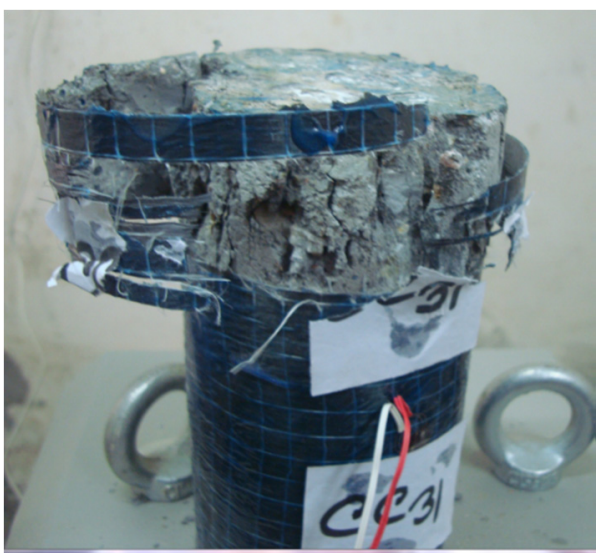

c)

Figure 14. Failure pattern of concrete specimens; a) plain concrete, b) JUTE-FRP wrapped specimen and c) CFRP wrapped specimen

\section{Conclusion}

In this experiment study attempt has been made to observe the behavior of FRP confined concrete cylinders after having been wrapped by two distinct FRPs, they are synthetic CFRP and FRP with natural Jute fiber. Observing the uniaxial behavior of those 26 cylinders, the following conclusion can be made: 
1) Among these two FRPs, CFRP appeared as quite effective for the strengthening of column by external wrapping when the column has a circular section. During seismic activity, strength and ductility of a column are two major aspects that need to be fulfilled and CFRP serve these two purposes quite satisfactorily. On the contrary, JUTE-FRP does not significantly increase the strength of the column and also the ductility is compromised especially for high strength concrete.

2) Stiffness of a column is also a vital issue when it is needed to prevent the formation of plastic hinges in a column. CFRP do increase the stiffness of the column to some extent especially for the high strength concrete. Whereas, JUTE-FRP is a softer material and cannot impart substantial stiffness to concrete column. But it has been noticed that JUTE-FRP does increase the strength and ductility of low strength concrete, so it can be said that Jute can be a good strengthening material for low strength concrete or brick masonry column.

3) Another noticeable role of CFRP was to alteration of brittle behavior of concrete with a ductile one, which is quite important to prevent catastrophic nature of failure of concrete column during accidental overloading at the time of seismic tremor.

4) CFRP can also be an effective strengthening/retrofitting material for columns having cross-section other than circular, but extensive study is needed to know more about the behavior.

\section{Acknowledgments}

The authors are thankful to Nippon steel \& Sumikin Materials Co. Ltd. Japan for their support in providing necessary CFRP sheet and epoxy resin, that have been used in this experiment.

\section{References}

Burgoyne, C., \& Balafas, I. (2007). Why is FRP not a financial success?. In Proc. 8th Intl. Conf. on FRP Reinforcement for Reinforced Concrete Structures, FRPRCS-8, Univ. of Patras, Patras, Greece.

Green, M. F., Bisby, L. A., Fam, A. Z., \& Kodur, V. K. R. (2006). FRP confined concrete columns: Behaviour under extreme conditions. Cement Concrete Compos, 28(10), 928-937.

Kumutha. R., Vaidyanathan. R., \& Palanichamy, M. S. (2007). Behaviour of reinforced concrete rectangular columns strengthened using GFRP. Cement Concrete Compos, 29(8), 609-615.

Malhotra, N., Sheikh, K., \& Rani, S. (2012). A review on mechanical characterization of natural fiber reinforced polymer composites. Journal of engineering research and studies, 3(1), 75-80.

NGCC. (2008). Sustainable FRPs: Naturally derived resins and fibres. NGCC Technical Sheet 08, Network group for composites in construction.

Parvin. A., \& Jamwal. A. S. (2005). Effects of wrap thickness and ply configuration on composite-confined concrete cylinders. Compos Struct, 67(4), 437-442.

Rahai, A. R., Sadeghian, P., \& Ehsani, M. R. (2008). Experimental behavior of concrete cylinders confined with CFRP composites. The $14^{\text {th }}$ World conf. on Earthquake Engineering. Oct. 12-17, Beijing, China.

Richart, F. E., Brandtzaeg, A., \& Brown, R. L. (1928). A study of the failure of concrete under combined compressive stresses. Bulletin No. 185, University of Illinois Engineering Experimental Station, Champaign, Ill; 1928.

Saatcioglu, M. (2010). Seismic design, chapter 6 of ACI design handbook (SI edition): Design of structural reinforced concrete elements in accordance with the strength design method of ACI318M-05. American Concrete Institute, Farmington Hills, MI., USA.

\section{Copyrights}

Copyright for this article is retained by the author(s), with first publication rights granted to the journal.

This is an open-access article distributed under the terms and conditions of the Creative Commons Attribution license (http://creativecommons.org/licenses/by/4.0/). 